\title{
Durapain in symptomatic treatment of severe acute pain: a post-marketing, prospective, multicenter, observational study - PRIME study
}

This article was published in the following Dove Press journal:

Journal of Pain Research

25 May 2017

Number of times this article has been viewed

\author{
Kshitij Shah' \\ Omvijay B Chaudhari ${ }^{2}$ \\ Palash Gupta ${ }^{3}$ \\ R Hom Chaudhuri ${ }^{4}$ \\ Ranjan Kamilya ${ }^{5}$ \\ Shreedhar S Kulkarni ${ }^{6}$ \\ S Subbaiah ${ }^{7}$ \\ Zubair H Sorathia ${ }^{8}$ \\ Gauri Billa9 \\ 'MS Orthopedic, Prime Hospital, \\ Andheri (West), ${ }^{2}$ Vatsalya Nursing \\ Home, Kalyan (West), Mumbai, \\ ${ }^{3}$ Dr. Palash Gupta Clinic, Rohini, \\ New Delhi, ${ }^{4}$ Homchaudhuri's Clinic, \\ ${ }^{5}$ Apollo Gleneagles Hospital, Kolkata, \\ West Bengal, ${ }^{6}$ Amrit Clinic, Matunga, \\ Mumbai, ${ }^{7}$ Subbaiah's Clinic, West \\ Mambalam, Chennai, ${ }^{8}$ Medicare \\ Hospital, Marol, Andheri East, \\ ${ }^{9}$ Medical Services, Abbott Healthcare \\ Pvt. Ltd, Mulund (West), Mumbai, \\ Maharashtra, India
}

Correspondence: Gauri Billa Medical Services, Abbott Healthcare Pvt. Ltd., Ist Floor, D-Mart Building, Mulund Goregaon Link Road, Mulund (West),

Mumbai 400080 , India

Tel +9l 2239537006

Email gauri.billa@abbott.com
Objective: To assess the effectiveness, overall tolerability, and gastrointestinal (GI) tolerability of Durapain (fixed dose combination of tramadol hydrochloride immediate release [50 $\mathrm{mg}$ ] and diclofenac sodium sustained release [75 mg]) in symptomatic treatment of severe acute pain in physician's routine clinical practice.

Materials and methods: In this prospective, multicenter, observational, post-marketing study, adult patients (aged 18-60 years) with severe acute pain were treated with tramadol hydrochloride/diclofenac sodium as per approved prescribing information. Evaluation was done at baseline, day 2, and day 5. Primary end point was pain intensity difference from baseline to day 5 . Results: A total of 351 patients (mean age 44.2 years; male $43 \%$; female $57 \%$ ) were included. The mean pain score was reduced from $9.2 \pm 1.09$ at baseline to $2.8 \pm 1.73$ at day $5(p<0.0001)$. The number of patients with severe intensity of pain reduced from $100 \%$ at baseline to $18.3 \%$ at day 2 and $6.96 \%$ at day 5 . According to the patient assessment, $68.36 \%$ of patients reported tolerability as "very good to good", whereas according to physician's assessment, "very good to good" tolerability was reported in $68.27 \%$ of patients. Five $(1.43 \%)$ patients discontinued the study because of adverse drug reaction. Five patients developed nine GI-related events of moderate intensity. Two patients developed three adverse reactions (burning sensation in urine, giddiness, and urine retention) other than GI events. No serious adverse drug reactions were reported during the study period.

Conclusion: Tramadol hydrochloride/diclofenac sodium is an effective and well-tolerated treatment in Indian patients with severe acute pain. Treatment with tramadol hydrochloride/ diclofenac sodium provides significant pain relief on day 2 and maintained until day 5 without any serious adverse reactions.

Keywords: Durapain, severe acute pain, tramadol and diclofenac combination

\section{Introduction}

Neurophysiology of acute pain resulting due to injury or surgery is a complex interplay of several dimensions including sensory, affective, cognitive, and behavioral aspects, ${ }^{1}$ making it difficult to achieve effective control with a single agent. ${ }^{1-3}$ Combining analgesics with different mechanisms of action and acting on peripheral and central pathways may help in providing pain relief at lesser dose of individual medicines, with better tolerability. ${ }^{4,5}$ For the management of moderate to severe pain, combination of opioid with nonsteroidal analgesics is required for better pain relief and possibly reduced dose of medicine. ${ }^{6}$

Tramadol, available worldwide since more than 4 decades, is effective and welltolerated treatment option for moderate to severe pain. ${ }^{7,8}$ Analgesia provided by tramadol is better than paracetamol and nonsteroidal anti-inflammatory drugs (NSAIDs); ${ }^{9,10}$ 
hence, it can be a suitable choice of analgesic for moderate to severe pain management. Diclofenac, the most frequently used NSAID, is considered as a gold-standard analgesic ${ }^{11,12}$ because of its efficacy compared with other NSAIDs. ${ }^{13}$ Apart from COX inhibition, diclofenac works by several other mechanisms, including inhibition of thromboxane-prostanoid receptor, lipooxygenase enzymes, peroxisome proliferatoractivated receptor gamma, substance $\mathrm{P}, \mathrm{N}$-methyl-D-aspartate receptor hyperalgesia, and acid-sensing ion channels. It also has effect on arachidonic acid release and uptake, nitric oxide-cyclic guanosine monophosphate antinociceptive pathway, and interleukin-6 production. ${ }^{14}$ Diclofenac is also effective for moderate to severe pain. ${ }^{1}$

In a comparative phase III trial, Durapain (fixed dose combination of tramadol hydrochloride immediate release [50 mg] and diclofenac sodium sustained release [75 mg], Abbott Healthcare Pvt Ltd, India), that is a fixed-dose combination (FDC) of immediate-release tramadol $50 \mathrm{mg}$ and sustained-release diclofenac $75 \mathrm{mg}$, has been shown to be effective in Indian population with moderate to severe pain due to acute musculoskeletal conditions, postoperative pain after orthopedic surgery, or an acute flare of osteoarthritis and rheumatoid arthritis. The combination was more efficacious than tramadol-paracetamol combination in Indian patients. ${ }^{15}$

In India, tramadol hydrochloride/diclofenac sodium is widely used for symptomatic treatment of severe acute pain. However, there are limited data on the use of tramadol hydrochloride/diclofenac sodium for the symptomatic treatment of severe acute pain due to different causes in real-life settings. A phase IV study might provide more insights into effectiveness and tolerability helping clinicians to effectively use this medicine in right patient type for better outcome.

\section{Objective}

The objective of the study was to assess the effectiveness, overall tolerability, and gastrointestinal (GI) tolerability of tramadol hydrochloride/diclofenac sodium tablet in symptomatic treatment of Indian patients with severe acute pain.

\section{Materials and methods}

This was a prospective, multicenter, observational, nonrandomized, noncontrolled, single-arm, post-marketing study. tramadol hydrochloride/diclofenac sodium was prescribed as per standard clinical practice of the treating physician. Adult treatment naïve patients aged between 18 and 60 years suffering from severe acute pain were enrolled in the study. Patients with known hypersensitivity to either tramadol or diclofenac or any of the excipients of product, pregnant women, lactating mothers, and patients with any other condition that precluded the use of tramadol hydrochloride/diclofenac sodium in a particular patient, in accordance with the prescribing information, were not included in the study. Tramadol hydrochloride/ diclofenac sodium was prescribed by the treating physician as per approved label (generally one tablet twice daily after meals or as directed by the physician for a period not exceeding 5 days). Evaluation of patients was carried out at baseline, and telephonic follow-up was performed on day 2. The second follow-up on day 5 was also done telephonically if the patients did not turn up for the visit. No additional laboratory tests or procedures were performed except those which treating physician felt necessary during routine practice. Concomitant medications other than those prohibited by the locally approved package insert were allowed. During follow-ups, intensity of pain, number of tramadol hydrochloride/diclofenac sodium tablets consumed on each day, overall tolerability, GI tolerability of study medicine, use of gastroprotective agents, and/or antiemetic and other analgesics during treatment were recorded. The intensity of pain was rated on a 4-point scale ( 0 , none; 1-3, mild; 4-6, moderate; and 7-10, severe). Global assessment of effectiveness and tolerability of treatment by patient and physician was noted at the end of the therapy. The global assessment of effectiveness and tolerability was performed on a scale of 1-7 (1, very good; 2, good; 3, fairly good; 4, moderate; 5 , slightly poor; 6 , poor; and 7 , very poor). The safety was also assessed by recording the adverse events. The primary end point of the study was pain intensity difference from baseline to day 5. The secondary end points included incidence of GI events; percentage of patients with severe GI events at each visit; percentage of patients who discontinued the treatment due to GI events; incidence of treatment-related events (other than GI events); percentage of patients using gastroprotective and/ or antiemetic during the study period; percentage of patients requiring analgesics during the study period; percentage of patients who rated the tolerability of treatment as "very good", "good", and "fairly good"; and percentage of physicians who rated the tolerability of treatment as "very good", "good", and "fairly good". The study was performed between January and April 2016 after approval from the respective zonal ethics committees, namely, Bangalore Ethics (South), Intersystem Biomedica Ethics Committee (West), Apollo-Gleneagles Hospital-IEC, Hurip Independent Bioethics Committee (East), and Good Society Ethical Research (North). Written informed consent was obtained from all patients.

\section{Statistical analysis}

Continuous variables were summarized with descriptive statistics, that is, number of observations, mean, and standard deviation. Categorical data were summarized as numbers and 
percentages. If the data were not available, then a missing category was presented.

A paired $t$ test was performed to examine change in pain score from baseline. All statistical tests were performed at a two-sided 5\% level of significance. A $p$-value of $<0.05$ was considered statistically significant. All the statistical analyses were performed with the SAS system, version 9.2 or later.

\section{Results}

This study included 351 patients with a mean age of 44.2 years from four cities (Chennai, Delhi, Kolkata, and Mumbai) and 19 centers in India. The percentage of male and female patients in the study was $43 \%$ and $57 \%$, respectively (Table 1 ).

Of the enrolled patients, $41.9 \%, 43.9 \%, 12 \%, 2.85 \%$, and $1.14 \%$ had musculoskeletal pain, joint pain, pain due to trauma, post-operative pain, and other pain, respectively. Seventy-five $(21.4 \%)$ patients had significant medical history, of which $65.3 \%$ of patients had a history related to cardiovascular system and $45.3 \%$ of patients had a history of endocrine/metabolic disorder. A total of 345 (98.3\%) patients completed the study as per protocol.

\section{Assessment of efficacy}

The mean pain score was reduced from $9.2( \pm 1.09)$ at baseline to $5.6( \pm 1.27)$ at day 2 with a mean difference of $-3.7 \pm 1.41$. The reduction in pain intensity at day 2 was statistically significant (Figure $1 ; p<0.0001$ ). At day 5 , the pain intensity score was reduced by $-6.4 \pm 2.18$ from baseline. The difference in pain intensity at day 5 from baseline was also statistically significant (Figure $1 ; p<0.0001$ ). Only one patient $(0.29 \%)$ required other analgesic (aceclofenac plus paracetamol) during treatment. Visit-wise distribution of patients with different pain intensities in evaluable population is shown in Table 2. The percentage of patients with severe intensity of pain reduced from $100 \%$ at baseline to $18.3 \%$ at day 2 and $6.96 \%$ at day 5 .

Table 3 shows the percentage of patients reporting the effectiveness of treatment as "very good", "good", and "fairly good" according to patient assessment and physician assessment.

Table I Baseline characteristics

\begin{tabular}{ll}
\hline Parameters & Result $(\mathbf{N}=\mathbf{3 5} \mathrm{I})$ \\
\hline Age, mean \pm SD (years) & $44.2 \pm 11.8$ \\
Gender, $\mathrm{n}(\%)$ & \\
$\quad$ Male & $15 \mathrm{I}(43)$ \\
$\quad$ Female & $200(57)$ \\
Height, mean \pm SD $(\mathrm{cm})$ & $161.6 \pm 6.89$ \\
Weight, mean \pm SD $(\mathrm{kg})$ & $68.5 \pm 10.12$ \\
\hline
\end{tabular}

Abbreviation: SD, standard deviation.

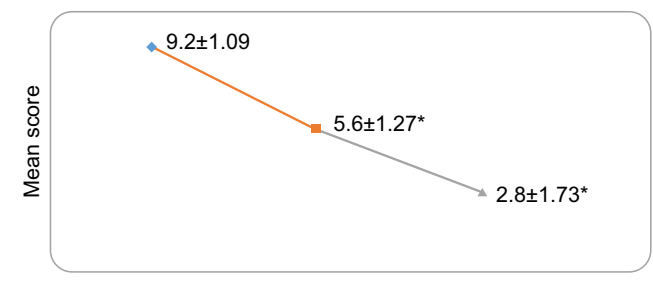

Figure I Pain intensity score from baseline to day 5 (evaluable population $\mathrm{n}=345$ ). Notes: ${ }^{*} p<0.0001$. Orange colour: Reduction in mean pain intensity score from baseline to day 2. Blue colour: Reduction in mean pain intensity score from day 2 to day 5 .

Table 2 Visit-wise distribution of pain intensity

\begin{tabular}{lllll}
\hline Visit & $\begin{array}{l}\text { No pain, } \\
\text { n (\%) }\end{array}$ & Mild, n (\%) & $\begin{array}{l}\text { Moderate, } \\
\text { n (\%) }\end{array}$ & $\begin{array}{l}\text { Severe, } \\
\text { n (\%) }\end{array}$ \\
\hline Baseline & - & - & - & $345(100)$ \\
Day 2 & - & $24(6.96)$ & $258(74.8)$ & $63(18.3)$ \\
Day 5 & II (3.19) & $272(78.8)$ & $38(11)$ & $24(6.96)$ \\
\hline
\end{tabular}

Table 3 Effectiveness of treatment as "very good", "good", and "fairly good" in evaluable population

\begin{tabular}{lll}
\hline $\begin{array}{l}\text { Effectiveness } \\
\text { of treatment }\end{array}$ & $\begin{array}{l}\text { Patient assessment, } \\
\mathbf{n = 3 4 5}(\%)\end{array}$ & $\begin{array}{l}\text { Physician assessment, } \\
\mathbf{n = 3 4 5}(\%)\end{array}$ \\
\hline Very good & $26(7.54)$ & $32(9.28)$ \\
Good & $184(53.3)$ & $185(53.6)$ \\
Fairly good & $115(33.3)$ & $101(29.3)$ \\
\hline
\end{tabular}

A total of $60.84 \%$ patients reported the effectiveness of treatment as "very good to good" as per patient assessment. Similarly, according physician assessment, "very good to good" effectiveness was observed in $62.88 \%$ of patients (Table 3 ).

A total of $22 \%$ patients required both gastroprotective agents and antiemetic treatment, whereas $31.6 \%$ required gastroprotective agent (Table 4).

Omeprazole, pantoprazole, and rabeprazole were the proton pump inhibitors (PPIs) and domperidone was the antiemetic that was prescribed to patients (Table 5).

\section{Assessment of safety}

According to the patient assessment in evaluable population, $68.36 \%$ of patients reported tolerability as "very good to good", whereas according to physician's assessment, "very good to good" tolerability was reported in $68.27 \%$ of patients and it was reported "fairly good" in $24.9 \%$ of patients (Table 6). Overall, $66.4 \%$ of patients required concomitant medications. Five patients $(1.42 \%)$ developed nine GI-related events, all of which were of moderate intensity. Abdominal pain three events $(0.8 \%)$, nausea two events $(0.6 \%)$, vomiting two events $(0.6 \%)$, diarrhea one event $(0.3 \%)$, and heartburn one event $(0.3 \%)$ were the GI events reported. All GI events were related to the study drug. In all 
Table 4 Use of gastroprotective and antiemetic agents in evaluable population

\begin{tabular}{ll}
\hline $\begin{array}{l}\text { Use of gastroprotective and antiemetic } \\
\text { agents }\end{array}$ & $\begin{array}{l}\text { Evaluable population, } \\
\mathbf{N = 3 4 5}(\%)\end{array}$ \\
\hline $\begin{array}{l}\text { Patients who used both gastroprotective } \\
\text { and antiemetics }\end{array}$ & $76(22.0)$ \\
$\begin{array}{l}\text { Patients who used gastroprotective } \\
\text { Patients who used antiemetics }\end{array}$ & $109(31.6)$ \\
\hline
\end{tabular}

Table 5 Summary of gastroprotective agents/antiemetics agents

\begin{tabular}{ll}
\hline Name of the drug class/molecule used & $\begin{array}{l}\text { Evaluable population, } \\
\mathbf{N}=\mathbf{3 4 5}(\%)\end{array}$ \\
\hline Gastroprotective agents & $109(31.6)$ \\
Omeprazole & $2(1.83)$ \\
Pantoprazole & $49(45.0)$ \\
Rabeprazole & $58(53.2)$ \\
Antiemetic agents & $76(22.0)$ \\
Domperidone & $76(100)$ \\
\hline
\end{tabular}

Table 6 Physician and patient assessment of tolerability in evaluable population

\begin{tabular}{lll}
\hline $\begin{array}{l}\text { Assessment of } \\
\text { tolerability }\end{array}$ & $\begin{array}{l}\text { Patient assessment, } \\
\mathbf{N}=\mathbf{3 4 5}(\%)\end{array}$ & $\begin{array}{l}\text { Physician assessment, } \\
\mathbf{N}=\mathbf{3 4 5}(\%)\end{array}$ \\
\hline Very good & $24(6.96)$ & $30(8.70)$ \\
Good & $212(61.4)$ & $209(60.6)$ \\
Fairly good & $93(27.0)$ & $86(24.9)$ \\
\hline
\end{tabular}

five patients who developed GI events, the study medication was discontinued. The adverse events were resolved after discontinuation of study medicine. Two patients developed three adverse reactions (burning sensation in urine, giddiness, and urine retention) other than GI events of which two were moderate in intensity and one was of mild severity. Study medication was discontinued in both patients. No serious adverse reactions were reported during the study period. Five $(1.42 \%)$ patients discontinued the study because of adverse drug reaction, whereas one patient was lost to follow-up. Of the patients who discontinued study, GI adverse events and other adverse events were reported in three $(0.85 \%)$ and two $(0.57 \%)$ patients, respectively. With discontinuation of the study drug, all adverse drug reactions were resolved.

\section{Discussion}

Pain is a common concern in patients for which they often consult health care professionals. The presence of multiple pain pathways and pain transmitter substances suggests the need for analgesic agents with different mechanisms. ${ }^{16}$ Paracetamol, NSAIDs, and opioids are the main analgesics used in clinical practice either alone or in combination. ${ }^{17}$ Of the several criteria, severity of pain is one of the important factors for the selection of analgesic by health care professionals. ${ }^{17}$ The tramadol plus diclofenac sodium FDC available in the Indian market is commonly used for the management of severe acute pain. Musculoskeletal conditions are a prevalent problem across the world and the most common cause of severe long-term pain and physical disability. ${ }^{18}$ The combination of tramadol plus diclofenac sodium has been evaluated in the management of moderate to severe acute musculoskeletal pain in a phase III trial. ${ }^{15}$ The results showed a significant reduction in the VAS score for overall pain with the tramadol $(50 \mathrm{mg})$ plus diclofenac $(75 \mathrm{mg})$ combination at day $3(p=0.001)$ and day $5(p<0.0001)$ compared with the tramadol $(37.5 \mathrm{mg})$ plus paracetamol $(325 \mathrm{mg})$ combination. Tramadol $(50 \mathrm{mg})$ plus diclofenac $(75 \mathrm{mg})$ tablet was given twice daily, whereas tramadol $(37.5 \mathrm{mg})$ plus paracetamol $(325 \mathrm{mg})$ was prescribed in the dose of two tablets every 4-6 hours, up to a maximum of eight tablets daily. ${ }^{15}$ In the current post-marketing observational study, we evaluated the effectiveness and safety of tramadol hydrochloride/diclofenac sodium in Indian patients with severe acute pain. Musculoskeletal pain was one of the most common causes of pain for prescribing tramadol hydrochloride/diclofenac sodium in our study. Joint pain and traumatic pain were the other two major causes of pain in our study population. The study design and patient population in our study were different than the previous study. ${ }^{15}$ First, we enrolled patients with severe pain and there was no comparative arm. Second, we did the first evaluation of efficacy and safety at day 2 unlike phase III trial in which patients were evaluated at day $3 .{ }^{15} \mathrm{We}$ observed statistically significant reduction in pain intensity at day $2(p<0.0001)$ from baseline. In line with the reduction in pain intensity, the number of patients with severe pain also reduced at day 2 and at day 5 from baseline. At day 5, only $6.96 \%$ of patients had severe pain compared with $100 \%$ at baseline. Patients with acute severe pain often expect faster pain relief. The significant effectiveness of tramadol plus diclofenac combination observed on day 2 is an important finding in this study. The efficacy was also assessed on the global assessment scale by both patients and physicians. Overall, our results are in accordance with the previously published results. ${ }^{15}$

A total of $93.43 \%$ patients reported effectiveness as "fairly good to very good" according to the patient assessment, whereas $91.44 \%$ of patients had "fairly good to very good" as per physicians assessment. The findings of physicians and patients assessment of effectiveness are almost similar.

Adverse effects can adversely affect the patient compliance. ${ }^{19}$ Overall, study medication was well tolerated by 
patients in this study. Only $1.42 \%$ of patients were discontinued from the study because of adverse drug reactions. No serious adverse reaction was reported in the study. NSAIDs are commonly associated with GI adverse effects. ${ }^{20}$ In our study, five patients reported nine events related to GI tract. Such adverse effects of NSAIDs can be significantly reduced by PPIs. ${ }^{21}$ In our study, gastroprotective agents in the form of PPIs were used in about one-third patient population. Rabeprazole was the most commonly prescribed PPI followed by pantoprazole. Omeprazole was used in less than $2 \%$ of patients.

Nausea and vomiting are important GI adverse effects associated with the use of tramdol, ${ }^{22}$ and they are dose dependent. ${ }^{23}$ Prophylactic antiemetic, such as metoclopramide, is useful in preventing such adverse events. ${ }^{7}$ In our study, antiemetic therapy was used in $22.6 \%$ of patients, all of whom were given domperidone. Overall, both gastroprotective agents and antiemetic treatment were prescribed in $22 \%$ of patients, and gastroprotective agent was prescribed in $31.6 \%$ of patients prophylactically.

Tolerability assessment performed by patient and physicians yielded similar findings. A total of $94.36 \%$ patients reported tolerability as "fairly good to very good" according to patients' assessment, whereas $93.17 \%$ of patients had "fairly good to very good" tolerability as per physician's assessment.

The published data on the efficacy and safety of tramadol plus diclofenac sodium combination are limited. The results of this study add to the existing knowledge about the effectiveness and safety of tramadol plus diclofenac sodium. Overall, our study provides interesting insights about the management of patients with severe acute pain with tramadol hydrochloride/diclofenac sodium in real-life settings.

The open-label, non-comparative design, absence of placebo group, and lack of blindness in the assessment of patients and doctors are the main limitations of our study. As pain is a subjective experience, the knowledge of patients could influence the results. Evaluation of therapy might be done by different methods for different types of pain. As this was an observational study, we mainly evaluated the intensity of pain and global assessment of effectiveness on a 7-point scale. The discontinuation rate of $1.42 \%$ was observed, despite giving prophylactic gastroprotective and antiemetic medications. The exact discontinuation rate in the absence of these agents is not known. We did not evaluate the impact of therapy on concomitant medication. Further studies are required to evaluate the impact of study medicine on the concomitant medication. The findings of our study should be interpreted considering these limitations.

\section{Conclusion}

Short-term therapy with tramadol hydrochloride/diclofenac sodium is effective and well tolerated in Indian patients with severe acute pain. tramadol hydrochloride/diclofenac sodium provides significant pain relief on day 2 and maintains until day 5 without any serious adverse reaction. The use of gastroprotective agents and antiemetic therapy helps to avoid GI-related events in these patients.

\section{Acknowledgments}

The authors would like to thank Dr. Pankaj Gupta and Dr. Rajnish Gupta from Delhi, and Dr. Suhas Shah, Dr. Rutuj Kamdar, Dr. Milind Patil, Dr. Shailesh Kamble, Dr. Pushkar Likhite, Dr. Faisal Bape, and Dr. Vikram Rajwadkar from Mumbai for their participation in this study. This study was funded by Abbott Healthcare Pvt Ltd.

Dr Gauri Billa, Medical Advisor, Medical Services has authored this publication in the capacity of employee of Abbott Healthcare Pvt Ltd. Dr. Kshitij Shah, Dr. Omvijay B Chaudhari, Dr. Palash Gupta, Dr. R. Hom Chaudhuri, Dr. Ranjan Kamilya, Dr. S.S. Kulkarni, Dr. S. Subbaiah, Dr. Zubair H Sorathia have co-authorized this publication. Financial support for the project was provided by Abbott Healthcare Pvt Ltd, India. Dr Gauri Billa is an employee of Abbott Healthcare Pvt Ltd, India.

\section{Disclosure}

The authors report no conflicts of interest in this work.

\section{References}

1. Derry P, Derry S, Moore RA, McQuay HJ. Single dose oral diclofenac for acute postoperative pain in adults. Cochrane Database Syst Rev. 2009;(2):CD004768.

2. McQuay H, Moore A, Justins D. Treating acute pain in hospital. BMJ. 1997;314:1531-1535.

3. Vanderah TW. Pathophysiology of pain. Med Clin North Am. 2007; 91:1-12.

4. Rawal N, Macquaire V, Catalá E, Berti M, Costa R, Wietlisbach M. Tra$\mathrm{madol} /$ paracetamol combination tablet for postoperative pain following ambulatory hand surgery: a double-blind, double-dummy, randomized, parallel-group trial. J Pain Res. 2011;4:103-110.

5. Raffa RB. Pharmacology of oral combination analgesics: rational therapy for pain. J Clin Pharm Ther. 2001;26(4):257-264.

6. Thakor NM, Bhavsar DN, Varde NM, Patel JK, Updhyay UM. Formulation and evaluation of bilayer tablet of tramadol hydrochloride and diclofenac sodium. Int J Chem Pharm Sci. 2013;1:128-146.

7. Lehmann KA. Tramadol in acute pain. Drugs. 1997;53(Suppl 2):25-33.

8. Radbruch L, Grond S, Lehmann KA. A risk-benefit assessment of tramadol in the management of pain. Drug Saf. 1996;15(1):8-29.

9. Dejonckheere M, Desjeux L, Deneu S, Ewalenko P. Intravenous tramadol compared to propacetamol for postoperative analgesia following thyroidectomy. Acta Anaesthesiol Belg. 2001;52(1):29-33.

10. Pagliara L, Tornago S, Metastasio J, et al. Tramadol compared with diclofenac in traumatic musculoskeletal pain. Curr Ther Res. 1997;58(8):473-480. 
11. Skoutakis VA, Carter CA, Mickle TR, et al. Review of diclofenac and evaluation of its place in therapy as a nonsteroidal antiinflammatory agent. Drug Intell Clin Pharm. 1988;22(11):850-859.

12. Babic-Naglic D. Voltaren - the gold standard. Reumatizam. 2000;47(2): 29-31.

13. Pavelka K. A comparison of the therapeutic efficacy of diclofenac in osteoarthritis: a systematic review of randomised controlled trials. Curr Med Res Opin. 2012;28(1):163-178.

14. Gan TJ. Diclofenac: an update on its mechanism of action and safety profile. Curr Med Res Opin. 2010;26(7):1715-1731.

15. Chandanwale AS, Sundar S, Latchoumibady K, et al. Efficacy and safety profile of combination of tramadol-diclofenac versus tramadolparacetamol in patients with acute musculoskeletal conditions, postoperative pain, and acute flare of osteoarthritis and rheumatoid arthritis: a Phase III, 5-day open-label study. J Pain Res. 2014;7: $455-463$.

16. Raffa RB, Pergolizzi JV, Tallarida RJ Jr. Analgesic combinations. J Pain. 2010;11(8):701-709.
17. Billa G, Gabhane M, Biswas S. Practice of pain management by Indian healthcare practitioners: results of a paper based questionnaire survey. Pain Res Treat. 2015;2015:891092.

18. Woolf AD, Pfleger B. Burden of major musculoskeletal conditions. Bull World Health Organ. 2003;81(9):646-656.

19. Jin J, Sklar GE, Oh VMS, Li SC. Factors affecting therapeutic compliance: a review from the patient's perspective. Ther Clin Risk Manag. 2008;4(1):269-286.

20. Pergolizzi Jr JV, van de Laar M, Langford R, et al. Tramadol/paracetamol fixed-dose combination in the treatment of moderate to severe pain. J Pain Res. 2012;5:327-346.

21. Kean WF, Buchanan WW. The use of NSAIDs in rheumatic disorders 2005: a global perspective. Inflammopharmacology. 2005;13(4): 343-370.

22. Schug $\mathrm{S}$. The role of tramadol in current treatment strategies for musculoskeletal pain. Ther Clin Risk Manag. 2007;3(5):717-723.

23. Dayer P, Desmeules J, Collart L. Pharmacology of tramadol. Drugs. 1997;53(Suppl 2):18-24
Journal of Pain Research

\section{Publish your work in this journal}

The Journal of Pain Research is an international, peer reviewed, open access, online journal that welcomes laboratory and clinical findings in the fields of pain research and the prevention and management of pain. Original research, reviews, symposium reports, hypothesis formation and commentaries are all considered for publication.

\section{Dovepress}

The manuscript management system is completely online and includes a very quick and fair peer-review system, which is all easy to use. Visit http://www.dovepress.com/testimonials.php to read real quotes from published authors. 